\title{
História e Cultura Afro-Brasileira: um olhar sobre a Lei 10639/2003 nas bibliotecas escolares
}

\author{
History and Culture Afro-Brazilian: a look at the Law 10639/2003 school libraries
}

\author{
Ana Claudia Emídio da Silva \\ Graduação em Biblioteconomia pela Universidade Federal do Ceará - UFC, campus Cariri. \\ E-mail: ana_claudia_ufc@yahoo.com.br
}

Maria Cleide Rodrigues Bernardino

Doutora em Ciência da Informação, pela Universidade de Brasília - UnB. Professora Adjunta do Curso de Biblioteconomia da Universidade Federal do Cariri - UFCA.

E-mail: cleide@cariri.ufc.br

\begin{abstract}
Joselina da Silva
Doutorado em Ciências Sociais pela Universidade do Estado do Rio de Janeiro - UERJ. Professora Adjunta do Curso de Biblioteconomia da Universidade Federal do Cariri - UFCA.

E-mail: joselinajo@yahoo.com.br
\end{abstract}

\begin{abstract}
Resumo
A proposta desse artigo vislumbra analisar as ações desenvolvidas pelas bibliotecas escolares das Escolas Estaduais de Juazeiro do Norte, Ceará, no que se refere à aplicação da Lei 10.639, de 9 de janeiro de 2003, que acrescentou e alterou respectivamente os artigos 26A e o 79B da Lei de Diretrizes e Bases da Educação Nacional (LDB). O primeiro refere-se à obrigatoriedade de todas as instituições de ensino fundamental e médio, públicas e privadas, incluírem, em seu currículo o ensino da "História e Cultura Afro-Brasileira, a luta dos negros no Brasil, a cultura negra brasileira e o negro na formação da sociedade nacional, resgatando a contribuição do povo negro nas áreas social, econômica e política pertinentes à História do Brasil”. O segundo artigo inclui no calendário escolar, vinte de novembro, como 'Dia Nacional da Consciência Negra'. Trata-se de uma pesquisa etnográfica de natureza qualitativa com delineamento bibliográfico, observação sistemática e entrevista. A pesquisa foi ambientada em bibliotecas das três maiores escolas estaduais, da cidade. Buscamos fazer um levantamento do acervo relativo à lei 10639/03. Procuramos também analisar a utilização daquele material, pelos docentes e discentes das instituições visitadas e contribuir com o reconhecimento da importância da biblioteca escolar como instrumento social e pedagógico, além de refletir sobre procedimentos de avaliação de seus serviços no processo de ensino. Neste sentido, perceber a biblioteca como mediadora da informação. Esta pesquisa foi desenvolvida no âmbito do Núcleo Brasileiro, Latino Americano e Caribenho de Estudos em Relações Raciais, Gênero e Movimentos Sociais - N'BLAC, da Universidade Federal do Cariri (UFCA).
\end{abstract}

Palavras-Chave: Biblioteca Escolar. Lei 10639/03. Centro de Multimeios.

\begin{abstract}
The proposal envisions this article analyze the actions taken by libraries Schools State of Juazeiro do Norte, Ceará, with regard to the application of Law 10.639, of January 9, 2003, which added and changed respectively to Articles 26A and 79B of Law of Guidelines and Bases of National Education (LDB). The first refers to the obligation of all institutions of elementary and high schools, public and private, include in their curriculum the teaching of "History and Afro-Brazilian struggle of blacks in Brazil, the Brazilian black culture and black in the formation of national society, rescuing the contribution of black people in the social, economic and political pertinent to the history of Brazil". The second article includes the school calendar, November 20, as 'National Day of Black Consciousness'. This is an ethnographic qualitative design with bibliography, systematic observation and interview. The research was set in the libraries of the three largest state schools in the city. We seek to survey the acquits Law 10639/03. Also sought to assess the use of that material by teachers and students of institutions visited and contribute to the recognition of the importance of the school library as a social instrument and teaching, and reflect on assessment procedures for their services in the teaching process. In this sense, perceive the library as a mediator of information. This research in conducted under the Brazilian Center, Latin American and Caribbean Studies in Race Relations, Gender and Social Movements - N'BLAC, Federal University of Cariri (UFCA).
\end{abstract}

Keywords: School Library. Law 10639/03. Multimedia Centre.

Bibl. Esc. em R., Ribeirão Preto, v. 2, n. 2, p. 1-16, 2014. 


\section{Introdução}

O papel de mediadora da informação é inegável à biblioteca escolar, uma vez em que esta atua como um lugar para a difusão dos saberes. A biblioteca escolar deve ser vista como uma ferramenta na difusão do conhecimento, por possuir meios para o aprendizado, a autonomia das decisões e principalmente o crescimento social, contribuindo para o desenvolvimento cultural dos indivíduos e dos grupos sociais. Côrte e Bandeira (2011, p. 6) afirmam que a biblioteca escolar,

[...] serve de suporte aos programas educacionais, atuando como um centro dinâmico, participando, em todos os níveis e momentos, do processo de desenvolvimento curricular e funcionando como laboratório de aprendizagem integrado ao sistema educacional.

A biblioteca como um organismo vivo e atuante em aspectos gerais certamente fará toda diferença na inclusão da temática exigida pela lei 10639/03 no cotidiano desses jovens e até mesmo de toda a comunidade escolar.

A Lei 10.639 sancionada em 09 de janeiro de 2003 representa uma grande conquista da sociedade através do movimento social negro, que há décadas luta contra a discriminação vivida pelos afrodescendentes aqui no Brasil. Em seu texto legal, altera a última Lei de Diretrizes e Bases da Educação Nacional (LDB), Lei nº 9.394 de 1996, trazendo à educação brasileira a inclusão do estudo de História e Cultura Afro-Brasileira, no currículo escolar, a ser ministrado em todas as disciplinas nas escolas de Ensino Fundamental e Médio das redes, pública e privada. Segundo a lei, os conteúdos referentes à História e Cultura Afro-Brasileira serão ministrados no âmbito de todo o currículo escolar, em especial, nas áreas de Educação Artística, Literatura e História do Brasil. Entretanto, todas as disciplinas da grade curricular, estão aptas a contê-la em seus programas (BRASIL, 2003).

A inclusão dessa temática no currículo é muito mais do que mais uma pauta a ser discutida, refere-se ao ser, às vivências cotidianas de jovens que sofrem em diversos momentos de sua vida preconceitos e muitos, incentiva a autoafirmação identitária.

Desse modo, buscamos entender qual o papel da biblioteca escolar na aplicação da mesma. Procuramos compreender quais as ações realizadas pelas bibliotecas escolares das escolas estaduais de Juazeiro do Norte, no Ceará, no que diz respeito à lei e aos trabalhos desenvolvidos por essas e seus gestores. Além disso, na busca desse entendimento surge uma discursão que há anos se configura, que é a presença dos Centros de Multimeios nas escolas. Embora o trabalho se aproprie do termo biblioteca escolar, o governo do estado do Ceará, 
apresenta uma terminologia diferente. Ora, entendemos que ainda hoje vive-se essa discussão, mas, na busca da quebra desse conceito. Em razão disso o presente artigo utilizará o termo Biblioteca Escolar ao invés de Centro de Multimeios.

\section{Biblioteca Escolar versus Centro de Multimeios}

Os Centros de Multimeios foram criados a priori como uma política para a transformação do ambiente escolar e de leitura em ambientes estimulantes de aprendizagem, com laboratórios de vivências construtivas e interativas. A ideia surgiu no primeiro governo Tasso Jereissati (1987-1990) com o Projeto Salas de Leitura/Bibliotecas Escolares, que de acordo com Carvalho (2007, p. 237) causou a desativação da "maioria das bibliotecas escolares com a demissão dos professores nelas lotados". Essas bibliotecas/salas de leitura foram reativadas posteriormente, porém sem uma política governamental que garantisse ou incentivasse a permanência dos funcionários. Mais tarde, o cenário nacional apresentava o Programa Nacional Salas de Leitura / Bibliotecas Escolares, - durante o governo Collor/Itamar Franco (1991-1994) -, com a proposta de favorecer o desenvolvimento do prazer da leitura em contraponto ao livro didático (CARVALHO, 2007).

Pensando em espaço interativos e que contasse com materiais de leitura e multimídia foi criada a Sala de Multimeios ou Centro de Multimeios, como preferem alguns, com a ideia de um espaço cuja função seria maior que o da biblioteca escolar, pois acreditavam que a biblioteca estava voltada apenas para livros e materiais impressos.

\footnotetext{
Multimeios são ambientes estimulantes de aprendizagem e funcionam como extensão da própria sala de aula, como laboratório de vivências interessantes e construtivas. Nestes centros, além dos materiais impressos tradicionais das bibliotecas, são reunidos materiais cartográficos, jogos pedagógicos, discos, fitas K7, CD-ROM, fotografias, instrumentos musicais, e materiais esportivos selecionados em função do currículo escolar e catalogados de maneira apropriada (CENTRO..., 2005, p. 3).
}

A ampliação da concepção da biblioteca escolar para Centro de Multimeios, previa, conforme documento publicado pela Secretaria de Educação do Estado do Ceará que contasse com três ambiente, sendo um espaço com Biblioteca, outro para Laboratório de Informática e outro para o Banco de Livros.

Destarte, o papel da biblioteca não é unicamente fornecer recursos informacionais, sabemos que existem políticas de materiais didático e paradidático para esses ambientes, com 
disponibilidade de materiais tanto para alunos quanto para professores e esses materiais farão uma grande diferença na aplicação da lei durante todo o ano letivo. Entretanto, ampliamos o conceito de biblioteca escolar para além da viabilidade de materiais educacionais, mas, como uma instituição cujo papel é incentivar a leitura e a reflexão de textos escritos ou não para a compreensão completa e atribuição de significação na íntegra.

\title{
Conforme as Diretrizes da IFLA/UNESCO,
}

\begin{abstract}
A biblioteca escolar proporciona informação e ideias fundamentais para sermos bem sucedidos na sociedade atual, baseada na informação e no conhecimento. A biblioteca escolar desenvolve nos estudantes competências para a aprendizagem ao longo da vida e desenvolve a imaginação, permitindo-lhes tornarem-se cidadãos responsáveis (DIRETRIZES..., 2006, p. 3).
\end{abstract}

A biblioteca escolar também deve colaborar com os professores como facilitadora no processo de ensino/aprendizagem, baseados também nesses subsídios (KUHLTHAU, 1999). Resta à biblioteca escolar conhecer e desenvolver seu papel na escola, entretanto, Corrêa et. al. (2002), reforça que "para que ela exerça suas funções de forma adequada e eficiente, há necessidade da permanência do profissional melhor habilitado e qualificado para sua gestão: o bibliotecário". Barros (2005) acrescenta ainda que "não há um reconhecimento visível e palpável desse profissional, uma vez que seu espaço muitas vezes é ocupado por outros profissionais nem sempre capacitados ou formados em Biblioteconomia". Neste sentido, vive-se entre dois paradoxos: a necessidade e reconhecimento da importância do bibliotecário para a gestão da biblioteca escolar; e a falta de reconhecimento por parte das autoridades e até mesmo do núcleo gestor da escola sobre a atuação desse profissional.

Em parte esta questão é devido à ideologia criada para os bibliotecários dentro da biblioteca escolar em pleno século XXI, infelizmente ainda se limita ao tratamento do acervo literário e a organização desse espaço, com essa ideia ultrapassada acaba caracterizando a ausência de investimentos, pois a biblioteca escolar não acaba sendo entendida como parte da escola e em muitos casos é a última no recebimento de verbas e incentivos. Por outra parte é algo mais amplo e global, vai da própria concepção do trabalho do bibliotecário ao conhecimento da sociedade sobre este profissional.

Neste sentido, procuramos deixar claro aqui que muito mais que um 'guardador de livros' a responsabilidade desses profissionais vão desde processamento técnico, circulação de materiais, políticas de desenvolvimento de acervo, há um papel social que deve ser atuante dentro do ambiente escolar na qual está inserido, respeitando sua diversidade e cultura, conforme corrobora Barros (2005, p.70-71): 
O bibliotecário ou profissional da informação apresenta competências que muitas vezes transcendem os conhecimentos da ciência e da tecnologia quando isso acontece, podemos chamá-lo de profissional-cidadão, porque suas ações evidenciam o posicionamento de agente de intervenção e transformação social. No parâmetro desses olhares o bibliotecário intervém para que haja, de fato, democratização social, em que o direito a participação do cidadão nos acontecimentos e ambientes sociais e públicos seja intensa e verdadeira.

Apesar do abandono do governo brasileiro não somente a escola mas a todo setor da qual a mesma está inserida como o caso da biblioteca, existe todo um processo histórico de luta para melhorias desses espaços, legislações foram criadas, movimentos foram realizados. Entretanto, a problemática ainda continua, as bibliotecas continuam sem bibliotecários e sem condições efetivas de funcionamento.

Em vista disso, surge em 2010, no intuito de modificar a atual realidade, a Lei $\mathrm{n}^{\mathbf{o}}$ 12.244, de universalização das bibliotecas escolares no Brasil, somente agora mais de uma década após a criação dos Centros de Multimeios, uma legislação específica, regulamenta a presença de bibliotecas em instituições de ensino em todo o país. Segundo a lei 12244/10 toda e qualquer escola, da rede pública ou privada, deve ter obrigatoriamente uma biblioteca em condições suficientes para atender o número de alunos matriculados. De acordo com a lei as instituições de ensino, consideram biblioteca escolar a coleção de livros, materiais de vídeo e documentos registrados em qualquer suporte destinados a consulta, pesquisa, estudo ou leitura. Tendo um acervo de livros na biblioteca com, no mínimo, um título para cada aluno devidamente matriculado.

Destarte, o sistema de ensino deve determinar a ampliação deste acervo conforme sua realidade, dentro dessas funções: orientações de guarda, preservação, organização e funcionamento das bibliotecas escolares. As escolas deverão desenvolver esforços progressivos para que a universalização das bibliotecas escolares, nos termos previstos nesta lei, sejam efetivados num prazo máximo de dez anos, respeitando a profissão do bibliotecário.

No que se refere à lei 10639/03 dentro das bibliotecas escolares, que é lócus da nossa pesquisa, o parecer do Conselho Nacional de Educação (CNE), em 2004, fala sobre a inclusão dessa temática, que deve ir além do cotidiano na sala de aula (CONSELHO..., 2004). A lei, em nenhum momento, se limita apenas a sala de aula. Entretanto, muitas ações se limitam a esse ambiente e partindo desse pressuposto podemos considerar as bibliotecas como uma ferramenta na disseminação desses conhecimentos e principalmente na implementação da referida lei. A biblioteca tem esse poder. Além disso, possui uma relação interpessoal com os alunos tanto quanto os professores. Porém, para que isso seja possível (CARMO, 2011, p. 33), 
indica que "da mesma forma que deve ocorrer formação especifica para auxiliar os professores no desenvolvimento de suas atividades, os bibliotecários também devem ser incluídos".

Tendo em vista que a escola também deve ter consciência de seu papel nesse processo, Arruda e Casarin (2009), afirmam que a biblioteca é instituição social responsável por assegurar o direito da educação a todo cidadão, deverá se posicionar politicamente, contra toda e qualquer forma de descriminação. E ela como mediadora deve dispor em seu acervo de subsídios que supram a necessidade de sua comunidade, promovendo a divulgação, desses materiais, a interação, desses com seus usuários, promovendo um diálogo. Para Nunes (2006, p. 80):

Embora a Lei 10.639 indique a sala de aula como o lugar privilegiado para a mudança das práticas educativas, estas podem ser ampliadas para os demais espaços educativos da escola. Nesse sentindo, a biblioteca escolar surge, também, como um lugar para a difusão de saberes no ambiente escolar, porém ainda é um depositório de livros.

As Diretrizes Curriculares Nacionais para a Educação das Relações Étnico-Raciais e para o Ensino de História e Cultura Afro-Brasileira e Africana destacam a importância da biblioteca como espaço para a promoção da educação das relações étnico-raciais:

\footnotetext{
O ensino de História e Cultura Afro-Brasileira e Africana, a educação das relações étnico-raciais, tal como explicita o presente parecer, se desenvolverão no cotidiano das escolas, nos diferentes níveis e modalidades de ensino, como conteúdo de disciplinas, particularmente, Educação Artística, Literatura e História do Brasil, sem prejuízo das demais, em atividades curriculares ou não, trabalhos em salas de aula, nos laboratórios de ciências e de informática, na utilização de sala de leitura, biblioteca, brinquedoteca, áreas de recreação, quadra de esportes e outros ambientes escolares (ABRAMOWICZ; BARBOSA; SILVÉRIO, 2006, p. 2).
}

Após a incontestável participação da biblioteca escolar na inclusão desses saberes, objetivamos com a pesquisa, descobrir quais as ações que estão sendo realizadas pelas bibliotecas escolares na aplicação da lei 10639/03. Se existem materiais didáticos e paradidáticos, ou em qualquer suporte de pesquisa, voltados à temática história e cultura afrobrasileira, disponíveis aos professores e alunos especialmente. Buscaremos entender como acontece à aquisição desse material, e a utilização por parte de seus usuários, qual a visão dos mesmos acerca da lei 10639/03, bem como qual a sua postura diante das possibilidades oferecidas pela biblioteca escolar como instrumento social e pedagógico.

A presença do profissional bibliotecário será de grande relevância na disseminação desses conhecimentos, o que temos nos dias atuais é a quebra de perfil criado para esse profissional. Há muitos anos o bibliotecário deixou de ser apenas 'o guardião' de livros, com 
o grande avanço da tecnologia deixou de centralizar seu olhar apenas as fontes impressas. Para que haja contribuições das bibliotecas escolares nesse sentido, é preciso incluí-las nos planejamentos pedagógicos para se estabelecer comunicação entre os setores integrantes da escola.

Interessa-nos também, saber como a escola tem se relacionado com os temas tratados pela lei. Com isso, objetivamos investigar como as escolas estão atuando diante da obrigatoriedade e urgência de ações, para efetivar esses conhecimentos dentro das salas de aula e principalmente os desenvolvimentos de projetos e ações realizados pelas bibliotecas escolares, com foco na lei 10639/03. Especificando verificar a presença e circulação do material referente à lei 10639/03, além de conhecer sua estrutura física, a rotina vivida por cada uma das bibliotecas, a equipe responsável e os projetos desenvolvidos pelos mesmos referente a aplicação da referida lei e onde está buscando apoio.

Pretendemos ainda, certificarmos da existência ou não de projetos voltados a temática dentro da escola em parceria com a Secretaria de Educação (SEDUC). Entendermos como se dá essa parceria e qual o papel da $19^{\mathrm{a}}$ Coordenadoria Regional de Desenvolvimento da Educação (CREDE) e compreender ainda como acontece à aquisição desse material.

\section{Procedimentos metodológicos}

A pesquisa se deu em duas etapas, sendo que o primeiro momento foram visitadas e analisadas dez bibliotecas escolas públicas pelo período de um mês e no segundo momento foram escolhidas três bibliotecas escolares, para compor o universo da pesquisa. Os critérios de escolha dessas escolas se deram inicialmente, por questões de distribuição geográfica da cidade, contemplando escolas centrais e periféricas. Outro ponto, foi a existência de materiais didáticos e suportes referentes à temática estudada. Sentimos a necessidade de conhecer detalhadamente cada uma dessas escolas, para melhor refletir sobre a avaliação dos serviços oferecidos. Percebendo a importância da biblioteca escolar como um instrumento eficaz na disseminação da informação.

Trata-se de uma pesquisa descritiva que segundo Gil (2009, p. 42) "têm como objetivo primordial a descrição das características de determinada população ou fenômeno ou, então, o estabelecimento de relações entre as variáveis". Uma de suas características está na utilização de técnicas padronizadas de coleta de dados, tais como o questionário, que conforme Marconi 
e Lakatos (2010) é um instrumento que apresenta algumas vantagens como: economia de tempo, abrangência, liberdade e uniformidade na avaliação; e a observação sistemática, descrita por Marconi e Lakatos (2010), como aquela que se realiza em condições controladas, como o objetivo de responder a questões preestabelecidas.

O método de desenvolvimento da pesquisa é o etnográfico que "consiste no levantamento de todos os dados possíveis sobre a sociedade em geral e na descrição, com a finalidade de conhecer melhor o estilo de vida ou a cultura específica de determinados grupos" (MARCONI; LAKATOS, 2010, p. 94). O objetivo da etnografia é combinar o ponto de vista do observador interno com o ponto de vista do observador externo, sendo baseado na observação, na descrição e no contexto do objeto, sendo ainda aberto e profundo. Esta última foi realizada em todas as bibliotecas estudadas, durante os turnos de funcionamento da biblioteca escolar.

Quanto aos procedimentos a investigação se caracteriza por uma pesquisa bibliográfica e documental, pois, conforme nos explica Cervo, et al., (2007, p. 60), "procura explicar um problema a partir de referências teóricas publicadas em artigos, livros, dissertações e teses". Quanto à natureza de análise a pesquisa é qualitativa e quantitativa, uma vez em que Richardson et al (2009), afirma que esta pode ser caracterizada como a tentativa de uma compreensão detalhada dos significados e características situacionais apresentadas pelos entrevistados. Os instrumentos de coleta de dados foram questionários, entrevista semiestruturada e observação sistemática, com o objetivo de levantar informações que apoiem a resolução do problema de pesquisa e auxilie a atingir os objetivos.

\section{Analise dos dados}

Foi aplicado um questionário nas escolas participantes da pesquisa, com os professores das disciplinas de Português, Geografia, História e Sociologia. Essas disciplinas dispõe de quatorze professores, foram contatados treze do qual doze responderam o questionário, em virtude da negativa de um dos professores. Os questionários foram entregues aos doze professores dos quais apenas sete devolveram. Os sete professores respondentes um ministra a disciplina de Geografia, três de Português, dois de Sociologia e um de História.

O questionário aplicado continha perguntas abertas e fechadas em um total de doze questões. A primeira pergunta, indagava sobre a utilização do Centro de Multimeios e sua 
frequência. A proposta da pergunta está em descobrir se os professores utilizam o centro de multimeios ou não, dessa forma é possível compreender a postura desses profissionais mediante a disponibilidade do acervo total.

Gráfico 1 - Utilização do Centro de Multimeios

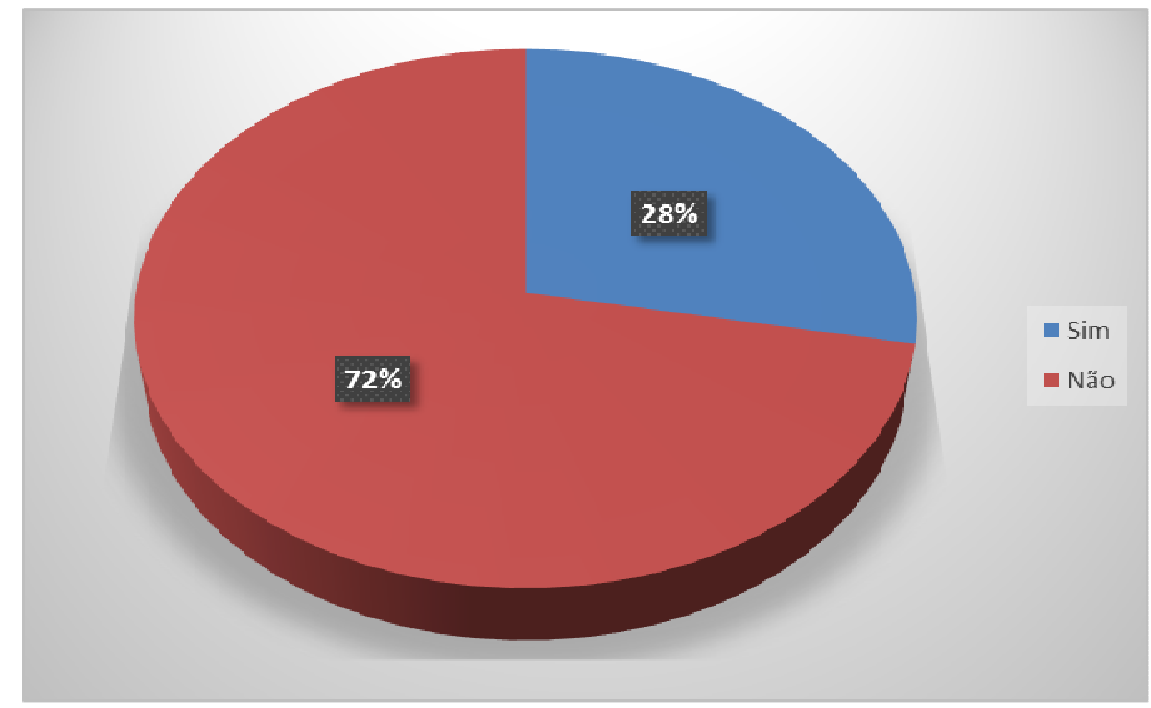

Fonte: As autoras.

Com o percentual de frequência de apenas $28 \%$ do universo de professores, coloca em cheque o conceito de Centro de Multimeios, que prometia um ambiente interativo de leitura para além da biblioteca escolar. O resultado deixa claro que não é a nomenclatura que muda uma imagem construída por anos e anos de descaso e contradições. A transformação da concepção de biblioteca escolar deve acontecer em sua essência, em seus serviços e comprometimento com a leitura e o conhecimento. A simples mudança do nome com que se chama este ambiente não se configura em uma mudança substancial do seu conceito.

A pergunta sobre o conhecimento da lei 10.639/03, que trata da obrigatoriedade do estudo de história e cultura afro-brasileira. 
Gráfico 2 - Professores que conhecem a Lei 10.639/03.

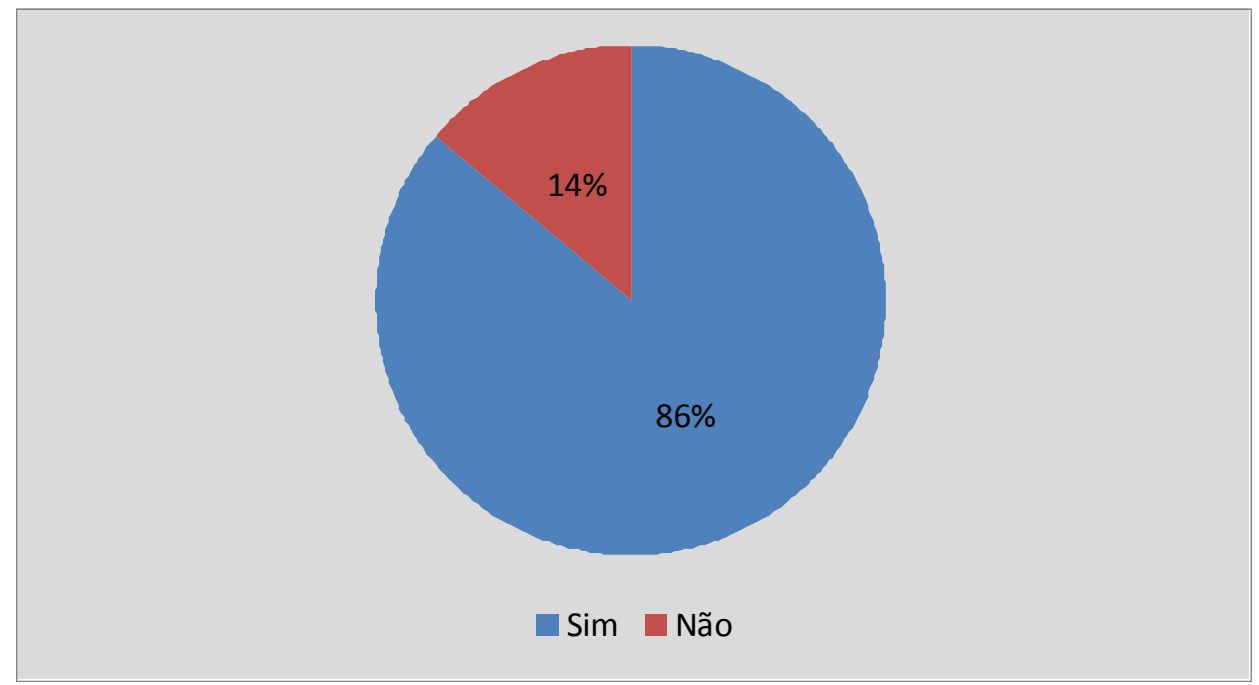

Fonte: As autoras.

Dos respondentes $14 \%$ não conhecem a Lei e $72 \%$ a conhecem. Partindo dessa resposta indagamos a opinião dos professores sobre o estudo da temática nas escolas de ensino médio. Dos professores que responderam 43\% concordaram, 43\% concordaram plenamente e $14 \%$ são indiferentes à importância do estudo de história e cultura afrobrasileira.

Quando indagados sobre os materiais presentes na Sala de Multimeios referentes a lei 10.369/03. Constatamos que $28 \%$ dos professores afirmam que existem materiais na biblioteca e esses podem contribuir nas atividades na sala de aula, já o mesmo percentual afirma que não existem tais materiais que possam contribuir nas atividades em sala de aula, referentes a lei, e 44\% não responderam essa pergunta, como ilustra o gráfico abaixo:

Gráfico 3 - Opinião sobre a existência de materiais referentes à lei 10639/03

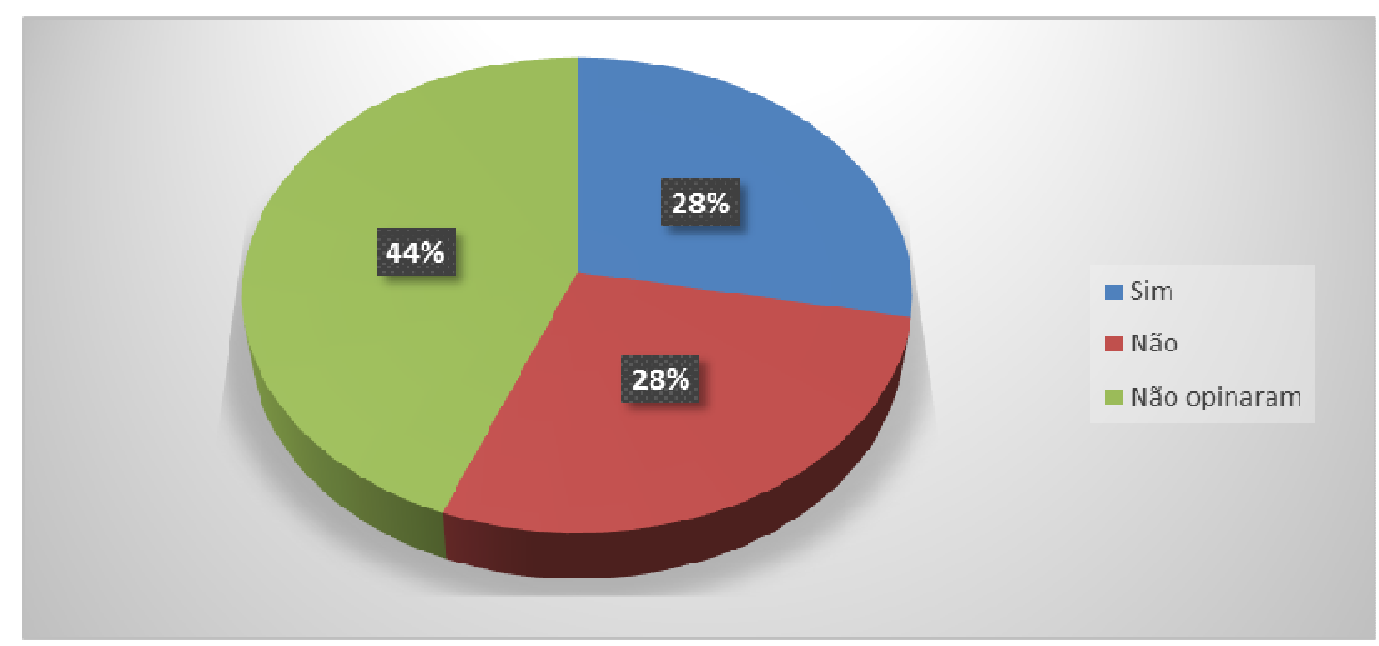

Fonte: As autoras.

Bibl. Esc. em R., Ribeirão Preto, v. 2, n. 2, p. 1-16, 2014. 
Além de conhecer a existência do acervo disponível na Sala de Multimeios, os respondentes também opinaram acerca das contribuições desses materiais em sala de aula. Conforme prevê a Lei a respeito da dia da Consciência Negra, todas as escolas mantém em seus calendários de eventos, atividades voltadas para este dia.

O quadro abaixo que traz as celebrações do dia da Consciência Negra nas escolas investigadas, resumimos as atividades realizadas por todas as instituições a partir do que cada escola realizou nas comemorações e as ações das Bibliotecas no desenvolvimento dos seus projetos.

Quadro 1 - Celebrações de 20 de Novembro

\begin{tabular}{|l|l|l|l|l|}
\hline ESCOLA & \multicolumn{1}{|c|}{ DATA } & PROJETO & \multicolumn{1}{|c|}{ ATIVIDADES } & \multicolumn{1}{|c|}{$\begin{array}{l}\text { ATIVIDADES } \\
\text { DA } \\
\text { BIBLIOTECA }\end{array}$} \\
\hline Escola 1 & 2011 & $\begin{array}{l}\text { Projeto } \\
\text { Negritude }\end{array}$ & $\begin{array}{l}\text { Pesquisa sobre personalidades } \\
\text { negras brasileiras }\end{array}$ & $\begin{array}{l}\text { Auxílio à } \\
\text { pesquisa, } \\
\text { ornamentação }\end{array}$ \\
\hline Escola 2 & $14 \mathrm{a}$ \\
$1911 / 2011$ & $11 / 2011$ & $\begin{array}{l}\text { Pesquisa sobre personalidades } \\
\text { negras, filme o contador de história, } \\
\text { dança e apresentação de alunos, } \\
\text { textos }\end{array}$ & $\begin{array}{l}\text { Auxílio à } \\
\text { pesquisa }\end{array}$ \\
\hline Escola 3 & $\begin{array}{l}\text { Danças afro, poesia, monólogo, } \\
\text { comidas típicas, filmes, } \\
\text { documentários em vídeo, painéis, } \\
\text { parodia, oficina de hip hop, roda de } \\
\text { samba }\end{array}$ & $\begin{array}{l}\text { Exposição de } \\
\text { livros auxilio em } \\
\text { pesquisas, } \\
\text { atividades } \\
\text { voltadas a } \\
\text { temática com } \\
\text { algumas turmas. }\end{array}$ \\
\hline
\end{tabular}

Fonte: As autoras.

O que podemos perceber no quadro a cima é a participação indireta das bibliotecas no desenvolvimento dessas atividades. É preciso mudar a ideia de biblioteca apenas como centro de pesquisa, mas para isso ela precisa se mostrar atuante nas diversas ações realizadas pela escola. As duas primeiras escolas possuem essa postura coadjuvante nessas ações, Na terceira encontramos ações diferenciadas. Nos questionamos sobre a possível passividade dessas duas escolas associadas à ideia desses gestores e da necessidade de se tratar o assunto nas escolas que atendem.

Sobre a seleção e aquisição do acervo, todas as bibliotecas pesquisadas não dispõem de verba específica para este fim e os materiais são adquiridos pelo Governo Estadual e Secretaria de Educação, através da CREDE 19. 


\section{Considerações finais}

Em linhas gerais percebemos que a realidade vivida pelas biblioteca escolar no contexto atual é visivelmente problemática. Desde sua estrutura física, seu acervo com materiais insuficientes para a demanda, entre tantos outros problemas vividos nesse ambiente. Usar a nomenclatura Centro de Multimeios pode ser aceito, porque muitos o utilizam por não conhecerem ou mesmo reconhecerem o real papel da biblioteca escolar e qual é a sua influência no meio onde está inserida.

Dentro das maiores dificuldades percebidas nas escolas, está à ausência de conhecimentos - dos profissionais que ali atuam - na gestão desses espaços. Uma das razões disso ocorrer são os responsáveis pela biblioteca. Esses acabam sendo professores de todas as áreas do conhecimento que estão em fim de carreira ou com algum problema sério de saúde e não pode mais estar em sala de aula, acabam sendo direcionados para a biblioteca, são os professores readaptados. Entretanto, não é dever dessa pesquisa cobrar desses profissionais conhecimentos específicos da área, sabemos que a sua presença nesse setor, em muitos casos não é opcional, suas carreiras não dão suporte a esse saber, pertencente à nós bibliotecários.

Nesse contexto, identificamos a concepção de desvalorização da classe bibliotecária, visível no discurso de alguns dos funcionários das bibliotecas durante a visita, que afirmaram que 'todos os professores são aptos a cuidar de uma biblioteca'. Essa fala, além de precipitada é equivocada, porque, durante o período da graduação, somos capacitados a lidar tecnicamente com diversos tipos de acervo, dentre eles o acervo da biblioteca escolar. Esses conhecimentos e práticas incluem, o estudo do usuário, inclusão de sistemas, layout da biblioteca, indexação, catalogação, classificação entre outras técnicas, serviços e suportes. Mesmo com capacitação de uma semana ou um mês, dada, pela Secretaria de Educação não dá propriedade a esses professores a gerir a biblioteca, como um bibliotecário o faria.

Porém o que mais ouvimos nas escolas visitadas, em se tratando das relações internas foi sobre a falta de comunicação. Nas bibliotecas escolares pesquisadas, professores afastados deixam de exercer a docência e passam atuar em outros serviços. Alguns dos professores em sala de aula, acabam não informando possíveis projetos ou ações aos regentes das Salas de Multimeios.

Sabemos que a lei 10639/03 dispõe de dois artigos, sendo que o Art. 26A que obriga a inclusão do ensino de História e Cultura Afro-Brasileira nas instituições de Ensino 
Fundamental e Médio, públicos e particulares. O segundo artigo o Art. 79B, que determina o dia 20 de novembro como do Dia da Consciência Negra, é o único que está sendo desenvolvido por todas as escolas. Mesmo que as bibliotecas não desenvolvam projetos, alguns estão ligados ao que a escola está realizando com parceiros.

Confirmamos isso, pois todas as escolas desenvolvem atividades, na culminância do dia 20 de novembro, contudo em duas delas as suas bibliotecas se limitam apenas a auxiliar na disponibilidade de material de pesquisa. Uma única biblioteca realiza práticas durante todo mês de novembro com alunos e professores. Entretanto, afirmamos que o dia da consciência negra deve ser trabalhada durante todo o ano letivo, quando a escola limita à apenas uma atividade realizada próxima ao final do ano. O ideal seria modificar essa postura e isso só será possível quando a escola se conscientizar do seu papel como mediadora na educação desses jovens.

Todavia alertamos para a relevância da participação da biblioteca escolar nesse processo, pois professores e educandos podem ter acesso à materiais sobre o ensino de história da África e sobre as relações étnico-raciais. Ao promover ações, a biblioteca só tem a ganhar em rendimento e em resultados. E muito, além disso, a biblioteca escolar pode e deve realizar discussões, rodas de debates a respeito das relações raciais dentro da escola, partindo do que rege a lei e ultrapassando os muros da escola.

Mas infelizmente quanto aos alunos, muitos nem sabiam que a lei existia ou que eram obrigatórias as aulas referentes ao assunto. Os discentes entendiam apenas como um momento de celebração vivido na escola em função da data, que em muitos dos casos, sequer sabiam o porquê da escolha da data ou a real razão dessa manifestação.

Nas exigências do Art. 26A, no que diz respeito a inclusão da temática, podemos perceber, que nas bibliotecas pouco se realiza. Vimos, em todos os casos estudados, há o incentivo de projetos voltados à leitura e o desenvolvimento da escrita. Sabemos da importância dessa temática e acrescentamos que é possível desenvolver nesses projetos os estudos étnicos raciais.

Destarte, identificamos também que essa lei foi assinada no inicio do ano de 2003, mas, somente em 2009 a matriz curricular foi modificada e a partir daí novas medidas foram tomadas. Em 2010 os materiais didáticos sobre a temática história e cultura afro-brasileira 
foram regularmente distribuídos em todas as instituições de ensino. Ou seja, sete anos após sua sansão.

Não estamos procurando culpados e sim compreendendo uma realidade, seja ela com grandes dificuldades de existir ou não, e nesse caso podemos dizer que ainda há muito a se fazer. Tentamos compreender como acontece essa quebra na realização de práticas dentro e fora de sala de aula, pois a procura pelo material é mínima, entretanto, não existe incentivo a sua utilização.

Não podemos esquecer também que essa falta de comunicação não é fator isolado. A ideia de biblioteca como espaço apenas para disponibilizar livros é ainda viva em boa parte das bibliotecas visitadas como foi mencionado anteriormente, essa visão retrógrada dificulta mais ainda o acesso à informação. Temos consciência da falta de conhecimento em práticas da biblioteconomia, não podemos cobrar desses docentes a formação que não tiveram. São professores que diante de uma adversidade acabaram indo a um setor que pouco frequentavam e muitos demonstram claramente a insatisfação por não estar em sala de aula.

No contexto da pesquisa pressupomos que o conhecimento técnico na área colaboraria imensamente com o continuo processo de aplicação da lei 10639/03. No trabalho desenvolvido testemunhamos que a biblioteca nunca deixou de existir dentro das escolas, o que falta é a construção de uma nova visão da mesma. Esse conhecimento contribuiria também nas práticas cotidianas, no tratamento adequado do acervo e no atendimento ao usuário, deixando explícito que essa é apenas uma pequena porcentagem do trabalho desenvolvido na biblioteca. É flagrante a falta de conhecimentos na prática de serviços de referência, disposição de materiais ou simplesmente divulgar junto aos docentes da existência de um acervo tão rico em informações e contribuição. 


\section{Referências}

ABRAMOWICZ, Anete; BARBOSA, Lúcia Maria de Assunção; SILVÉRIO, Valter Roberto. (Org.). Educação como prática da diferença. Campinas: Autores Associados, 2006.

ARRUDA, Darlane Darlene Nunes; CASARIN, Helen de Castro Silva. Utilização da biblioteca escolar na educação por professores do ensino fundamental das escolas municipais da cidade de Garça-SP. In: CONGRESSO DE INICIAÇÃO CIENTÍFICA DA UNESP, 21., 2009, São José do Rio Preto, SP. Anais... São José do Rio Preto: UNESP, 2009. Disponível em: <http://prope.unesp.br/xxi_cic/27_31252813856.pdf>. Acesso em: 22 out. 2013.

BARROS, Flávia Roberta dos Santos. O bibliotecário e o compromisso social: quais as possibilidades para a realização desse encontro. In: SOUTO, Leonardo Fernando (Org.). $\mathbf{O}$ profissional da informação em tempos de mudanças. São Paulo: Alínea, 2005. p.17-38.

BRASIL. Casa Civil. Lei 10.639, de 09 de janeiro de 2003. Diário Oficial [da] República Federativa do Brasil. Poder Executivo, Brasília, DF, 10 jan. 2003. Disponível em: $<$ http://www.planalto.gov.br/ccivil_03/leis/2003/110.639.htm>. Acesso em: 22 out. 2013.

CARMO, Nicácia Lina do. História e cultura afro-brasileira: um olhar sobre o acervo das Bibliotecas Públicas do CRAJUBAR. 2011. 57f. Trabalho de Conclusão de Curso (Graduação em Biblioteconomia) - Universidade Federal do Ceará, Campus Cariri, Juazeiro do Norte, 2011.

CARVALHO, Ana Maria Sá de. Políticas de leitura e biblioteca: na contracorrente da formação do leitor. In: BENTES PINTO, Virgínia; CAVALCANTE, Lídia Eugênia; SILVA NETO, Casemiro (Org.). Ciência da informação: abordagens transdisciplinares, gêneses e aplicações. Fortaleza: Edições UFC, 2007. p. 225-261.

CENTRO de multimeios: capacitação: manual 1. Fortaleza: SEDUC, 2005. Disponível em: $<$ www.crede10.seduc.ce.gov.br/.../62-chamada-pblica-2012?...centros-de-multimeios.pdf $>$. Acesso em: 22 out. 2013.

CERVO, Amado Luiz et al. Metodologia científica. 6. ed. São Paulo: Prentice Hall, 2007.

CONSELHO Nacional de Educação. Conselho Pleno. Resolução ${ }^{\circ}$ 1, de 17 de junho de 2004, que homologa o Parecer CNE/CP n ${ }^{\circ}$ 03, de 10 de março de 2004, sobre as Diretrizes Curriculares Nacionais para a Educação das Relações Étnico-Raciais e para o Ensino de História e Cultura Afro-Brasileira e Africana. Diário Oficial [da] República Federativa do Brasil. Poder Executivo, Brasília, DF, 19 maio. 2004. Disponível em: $<$ http://portal.mec.gov.br/cne/arquivos/pdf/003.pdf>. Acesso em: 23 out. 2013.

CORRÊA, Elisa Cristina Delfini et al. Bibliotecário escolar: um educador? Revista ACB, v. 7, n. 1, p. 107-123, 2002. Disponível em: <http://revista.acbsc.org.br/racb/article/view/379/459>. Acesso em: 22 out. 2013.

CÔRTE, Adelaide Ramos e; BANDEIRA, Suelena Pinto. Biblioteca escolar. Brasília: Briquet de Lemos, 2011. 
DIRETRIZES da IFLA/UNESCO para bibliotecas escolares, 2006. Disponível em: $<$ http://www.ifla.org/files/assets/school-libraries-resource-centers/publications/school-libraryguidelines/school-library-guidelines-pt.pdf>. Acesso em: 22 out. 2013.

GIL, Antonio Carlos. Métodos e técnicas de pesquisa social. 5. ed. São Paulo: Atlas, 2009. .

KUHLTHAU, Carol Collier. O papel da biblioteca escolar no processo de aprendizagem. In: VIANNA, Márcia Milton; CAMPELLO, Bernadete; MOURA, Victor Hugo Vieira.

Biblioteca escolar: espaço de ação pedagógica. Belo Horizonte: EB/UFMG, 1999. p. 9-14.

MARCONI, Marina de Andrade; LAKATOS, Eva Maria. Fundamentos de metodologia científica. 7. ed. São Paulo: Atlas, 2010.

NUNES, Cícera. A Lei nº 10.639/03 no currículo escolar: contribuições para o ensino da história e cultura africana e afrodescendente. In: ENCONTRO REGIONAL DE ESTUDANTES DE DIREITO E ENCONTRO REGIONAL DE ASSESSORIA JURÍDICA UNIVERSITÁRIA, 21., 2008, Crato, CE. Anais...Crato, CE: Fundação Araripe, 2008. Disponível em: <http://www.urca.br/ered2008/CDAnais/pdf/SD1_files/Cicera_NUNES.pdf>. Acesso em: 20 jan. 2012.

RICHARDSON, Roberto Jarry et al. Pesquisa social: métodos e técnicas. 3. ed. São Paulo: Atlas, 1999. 